Joking with customers in the service encounter has a negative impact on customer satisfaction: Replication and extension

Magnus Söderlund ${ }^{1}$ and Eeva-Liisa Oikarinen ${ }^{2}$

${ }^{1}$ Corresponding author: Stockholm School of Economics, P.O. Box 6501, SE-113 83, Stockholm, Sweden, Magnus.Soderlund@hhs.se, telephone: +46-8-736 9541.

${ }^{2}$ Oulu Business School, University of Oulu, Oulu, Finland, eeva-liisa.oikarinen@oulu.fi 


\title{
Joking with customers in the service encounter has a negative impact on customer satisfaction: Replication and extension
}

\begin{abstract}
Previous research has indicated that employee joke-telling in the service encounter can have a negative impact on customer satisfaction, particularly with respect to perceived overall message relevance as a mediating variable. The present study is an attempt to examine if these results would be replicated in service encounter settings with other characteristics. Two experiments were conducted, and the previous pattern was reproduced: customer satisfaction was reduced when employees told jokes compared to when jokes were not told. The results also indicate that employee joke-telling reduced both perceived relevance and positive affect, and that these two variables mediated the association between employee joke-telling and customer satisfaction. The results should be seen in contrast to several humor studies in an advertising context showing that humor-comprising ads can have positive effects on the receiver. One main reason for the differences is that a service encounter typically includes also other elements than humor in the employee's communication with a customer, and that employee humor usage attenuates the customer's attention to and comprehension of those other elements.
\end{abstract}

\section{Introduction}


Our point of departure is a set of recent studies by Söderlund et al. (2017) showing that when employees tell jokes to customers in service encounters, customer satisfaction is affected negatively. These results, however, should be seen in contrast to the suggestion that employee use of humor in service encounters can generate positive customer responses (Robert and Wilbanks, 2012). The Söderlund et al. (2017) results also appear to be at odds with findings in studies of the impact of humor in an educational context, indicating that educators who use humor in their classes are more positively rated and produce enhanced learning (Garner, 2006; Wanzer and Frymier, 1999). Moreover, the Söderlund et al. (2017) results seem to be in conflict with advertising research in which ad humor typically produces positive effects on several variables related to the ad itself and the advertised product (Eisend, 2009; Muehling and McCann, 1993; Smith, 1993; Sternhal and Craig, 1973; Weinberger and Gulas, 1992). In addition, it may be noted that some authors have claimed that humor can distract receivers from counterarguing (Cline and Kellaris, 1999; Cline et al, 2003) and reduce resistance (Strick et al., 2012), and therefore humor would have a positive persuasive potential (Lyttle, 2001).

The main explanation for negative effects in a service encounter setting offered by Söderlund et al. (2017) was that customer-employee conversations comprise also other content than jokes (typically, the share of this other content is larger in a service encounter conversation compared to an ad), that jokes reduce the perceived relevance of the employee's overall message, and that this in turn attenuates customer satisfaction. Thus, a main argument (and an empirical finding) in Söderlund et al. (2017) was that perceived message relevance mediated the impact of employee joke-telling on customer satisfaction. These results, however, were obtained in service encounter settings with several specific characteristics, which calls for more research. The present two studies (Study 1 and Study 2) should be seen as attempts to replicate and extend the previous findings in the context of other service encounter settings along the lines indicated below.

First, the Söderlund et al. (2017) service encounter manipulations comprised employee joketelling in the pre-purchase phase of the consumer's decision-making process. In conceptual terms, however, it is unclear if jokes from an employee would have the same impact before and during the consumption of services. For example, consumers may be particularly sensitive to interference by incongruent elements (such as humor) once consumption has started, and if this is the case the Söderlund et al. (2017) results may have underestimated the negative impact of employee joke-telling. To examine the potential for different effects due to when employee humor usage occurs in relation to the customer's purchase process, both 
Study 1 and Study 2 in the present study were carried out in a context in which jokes were delivered by employees once the service consumption had started.

Second, the Söderlund et al. (2017) results were generated by an examination of service encounters with relatively long customer-employee conversations comprising an overall theme. Such settings are likely the boost the negative influence of employee joke-telling, in the sense that jokes (which by definition comprise incongruence and demand more elaborated information processing) can interfere with the customer's understanding given that a particular theme calls for attention. Yet many service encounters are brief (Ketrow, 1991) and with no room for a theme to be communicated. In such settings, jokes may not have a negative impact on customer satisfaction. To assess this in the present study, Study 1 comprised employee joke-telling in a short service encounter in which no theme was communicated.

Third, the humor manipulations in Söderlund et al. (2017) comprised jokes in terms of stories about third parties. That is to say, employee $\mathrm{X}$ told customer $\mathrm{Y}$ a fun story about person $\mathrm{Z}$. However, this introduces the mindstates of others than the joke-teller and the listener, and there is a limit to how many such mindstates one can deal with before becoming overtaxed (Dunbar et al., 2016). Moreover, when a joke is a story, it may stand out as a particularly distinct - and incongruent - element in relation to the other elements in a conversation. The story format may also result in receiver absorption (Green and Brock, 2000), which means that other information than the story itself is likely to receive less attention (Agarwal and Karahanna, 2000; Buselle and Bilandzic, 2009). It is thus possible that joking in the specific form of story-telling has a particularly strong potential to reduce perceived relevance and, in the next step, to reduce customer satisfaction. To assess the replicability of the Söderlund et al. (2017) with respect to this aspect, the present Study 1 examined employee jokes in terms of storytelling. Moreover, to assess if the result would be the same for other types of jokes, Study 2 comprised jokes in terms of employee remarks here and there with the intention of being fun rather than storytelling.

Fourth, the Söderlund et al. (2017) findings were obtained in settings comprising a traditional service encounter in which the employee and the customer are the only interacting parties. In many service contexts, however, several customers are present and consume the service together (e.g., a group of tourists with the same guide and a group of gym class participants with one instructor). That is to say, in some service contexts customers are a (temporary) 
group. In such situations, particularly when coaching and counseling are parts of the service offer, it is possible that employee joke-telling can have positive effects on various grouprelated variables (e.g., perceived team spirit and perceived employee support for team members), and they can affect customer satisfaction positively. The present Study 2 was an attempt to examine this aspect.

In addition, Söderlund et al. (2017) found that employee joke-telling did not have a significant impact on customer affect. This finding is in contrast with several previous studies suggesting that humor is positively associated with positive affect (Eisend, 2009; Eisend, 2011; Lee and Mason 1999; Moran and Massam, 1999; Skalski et al., 2009). The reason why a humor-affect link did not materialize in Söderlund et al. (2017) may be the combination of (a) relatively long conversations with much other content than humor and (b) humor appearing as a discrete element in a specific part of the employee-customer conversation. Given that affect is an ephemeral state of mind, these conditions may have caused affect to disappear while additional content (without humor) appeared in the employee-customer conversations. To address this in the present study, we re-examine the possibility of an employee humor-customer affect link in both Study 1 (in which the conversation was short) and Study 2 (in which the employee use of humor appeared at several points in the conversation).

The purpose of the present study, then, is to re-examine the link between employee joketelling and customer satisfaction in additional service encounter settings by taking the aspects above into account. The present study is a response to the call for replications made by several authors (e.g., Easley et al., 2000; Evanschitzky et al., 2007). This call should be seen in the light of recent concerns that many findings in management-related areas may not be replicable (Evanschitzky and Armstrong, 2013). To this end, and as already indicated, two empirical studies (Study 1 and Study 2) were conducted. Since the service encounter settings explored in these experiments comprise other specific characteristics than in Söderlund et al. (2017), they should not be seen as duplications of the previous studies but as an attempt to see if the previous results would generalize to humor usage and service encounters with different characteristics. One main rationale for re-addressing the impact of employee humor usage in service encounters is that several authors have observed that humor is often a part of what the employee says in conversations with customers (Gilliam et al., 2014; Gwinner et al., 1998; Locke, 1996; Pearce, 2009). So far, however, there have been few empirical attempts to assess how employee humor influences customers. 


\section{Theoretical framework}

\subsection{Humor, joke-telling, and incongruity}

There are many types of humor (Bryant et al., 1980; Speck, 1991; Weinberger and Spotts, 1989), so employee humor usage in a service encounter can express itself in several ways. Here, our focus is on joke-telling embedded in a conversation in the course of normal interactions (Boxer and Cortés-Conde, 1997; Norrick, 1994; Robert and Wilbanks, 2012), because this appears to be a particularly common form for employees to joke with customers (Gilliam et al., 2014; Gwinner et al., 1998; Locke, 1996). Moreover, for our purposes here, jokes are any communication with a witty or funny intent known in advance by the teller (Duncan, 1982). In our two empirical studies, we examine the impact of two types of employee joke-telling embedded in conversations: (1) a joke in the form of a story about a third party appearing once, in the midst of a conversation (Study 1), and (2) brief comments intended to be fun that appear in several places within the same conversation (Study 2). In conceptual terms, however, and in this section, we assume that both types affect the same response variables.

Our main assumption, thus for both types of jokes in focus here, is that joke-telling in a conversation involves incongruity. We also assume that there are two ways for incongruity to manifest itself. First, it is assumed that jokes share a main component with other forms of humor, namely incongruity in terms of deviations from expectations (Alden and Hoyer, 1993; Duncan and Feisal, 1989; Lee and Mason, 1999; Meyer, 2000; Spotts et al., 1997). This thus means that joke-telling in a conversation comprises incongruity in the sense that jokes per se, by definition, are characterized by incongruity. Second, a joke represents a bounded speech act (Boxer and Cortés-Conde, 1997), and when it appears in a conversation it can be seen as a discrete conversational element in relation to other elements. This, then, introduces a potential incongruity aspect also with respect to the relation between the joke and other things said by a joke-teller in a conversation.

2.2 Incongruity, information processing, and perceived relevance

Several authors have argued that humor-based incongruency leads to increased attention (Cline and Kellaris, 1999; Cline et al., 2003; Eisend, 2011; van Kuilenburg et al., 2011; 
Smith, 1993) and more elaborated cognitive processing (Cline and Kellaris, 1999; van Dolen et al. 2008, Eisend, 2011). Given the effort involved in processing incongruent stimuli (Heckler and Childers, 1992), and given limited cognitive resources and effort-avoidance tendencies in information processing (Garbarino and Edell, 1997), however, humor elements in a message can reduce attention to and comprehension of other elements appearing in the same message (Cline et al. 2003; Krishnan and Chakravarti, 2003; Lyttle, 2007; Smith, 1993, Strick et al., 2012; Wood et al. 2011). Eisend (2011) refers to this as a "vampire effect”. In other words, humor can have a psychological distracting effect and diverts attention to itself (Eisend, forthcoming). Findings suggesting a pattern of this type are presented in Bryant et al. (1981); their data suggest that humor in textbooks may impair learning with respect to material unrelated to humor. Similarly, it has been shown that humor in ads attenuates memory for advertised products and brand names (Hansen et al., 2009). Thus humor may harm overall comprehension (Houston et al., 1987).

Here, we use the construct perceived relevance as an indicator of the distracting potential of jokes. In the advertising literature, relevance is sometimes referred to as how useful, important, or valuable a message is for the receiver (e.g., Laczniak et al., 1989). However, here we conceptualize relevance in another sense, namely how well integrated message elements are (Ang et al., 2007; Lee and Mason, 1999). A high level of relevance means that message elements work in concert with each other to convey a singular message (Ang et al., 2007). In other words, in a highly relevant message all components contribute to the main message communication (Heckler and Childers, 1992; Lee and Mason, 1999). Previous research has examined this in terms of, for example, how integrated verbal copy and pictures are in ads (Houston et al., 1987). Yet our focus here is on the level of integration of different verbal elements (jokes vs. other content) in what a sender says in a conversation.

Given that the incongruity involved in being exposed to jokes can reduce the receiver's attention to - and processing of - other elements in a message in which the jokes appear, we assume that jokes attenuate the receiver's perceptions of relevance of the overall message. It should be noted that a service setting is likely to impose special attention and comprehension requirements on the customer compared to receiving an ad, because in a service encounter the customer typically has less knowledge about the service and possible solutions and alternatives than the employee (Webster and Sundaram, 2009). 
An additional reason why employee joke-telling can reduce perceived relevance has to do with the nature of comprehension in a face-to-face context, because in this context exposure to humor calls for understanding not only of the humor per se (e.g., the meaning of a joke), but also for understanding why humor is used by the other party. Indeed, there are many social motives for humor usage, such as desire to bond, reduce tension, control of others, and status differentiation (Boxer and Cortés-Conde, 1997; Meyer, 2000; Norrick, 2009; Ziv, 2010). And in evolutionary terms, humor usage may reveal mating preferences (Eisend, forthcoming). We assume that the potential for such motives - which can be positively and negatively charged - encourages the receiver to make sense of humor usage (thus not only of humor per se) in such a way that attention to and comprehension of other parts of the conversation is compromised.

Given that people's cognitive processes are limited by a central resource that is taxed by multiple sense-making activities, and that this would reduce performance on one or all of the sense-making tasks (Beal et al., 2005), the task of the receiver to understand both jokes per se and why they are used in a conversation suggests a negative impact of employee joke-telling on perceived relevance. Thus we hypothesize the following:

H1: Employee joke-telling in face-to-face interactions with the customer reduces the customer's perceptions of the relevance of what the employee says

\subsection{Perceived relevance and customer satisfaction}

Prior research, in an advertising setting, shows that perceived relevance has a positive impact on evaluations of the ad and the advertised brand (De Keyser et al., 2015; Lee and Mason, 1999). Presumably, this association is mediated by comprehension, because relevance facilitates understanding of messages (Heckler and Childers, 1992) and, again in an advertising setting, understanding of ads has been shown to be positively associated with ad evaluations (Phillips, 2000). Thus, when relevance is reduced, we expect reduced levels of overall message evaluations. Moreover, in a face-to-face setting, several social norms exist with respect to the components of what a sender says to a receiver in a conversation (Skowronski and Walker, 2004), and breaking such norms could attenuate the receiver's evaluation of the message. Indeed, one of the norms is to "keep it relevant" (ibid.). If employee joking reduces perceived relevance (i.e., H1), we would expect that joking has a negative influence on the customer's message evaluations due to breaking norms for social discourse. In addition, joking may violate two other 
norms, namely "keep it brief" (jokes adds length to a message) and "keep it understandable" (humor can be seen as a "little intelligence test"; Norrick, 1994). Taken together, then, we expect that reduced perceived relevance attenuates evaluations of a message.

In the next step of the consumer's information processing activities, we assume that message characteristics (such as perceived relevance) have a valence-congruent impact on the customer's overall evaluations of the firm in which the employee works. This is consonant with a common assumption in the service literature, namely that the employee is the firm from the customer's point of view (Bitner et al., 1990; Webster and Sundaram, 2009). It is also consonant with the notion that conversation is a key element in employee-customer encounters (Grewal et al., 2002; Webster and Sundaram, 2009). In the present study, customer satisfaction represents our overall firm evaluation variable.

Given that employee joke-telling reduces perceived relevance (H1), and given that the characteristics of the employee's message to the customer in a face-to face setting has an impact on customer satisfaction, we assume that employee joke-telling has a negative impact on customer satisfaction:

H2: Employee joke-telling in face-to-face interactions with the customer reduces customer satisfaction

Our reasoning with respect to $\mathrm{H} 1$ and $\mathrm{H} 2$ implies that the impact of employee joke-telling on customer satisfaction is mediated by perceived relevance, so we also hypothesize the following:

H3: The impact of employee joke-telling on customer satisfaction is mediated by perceived relevance

2.4 Affect as an additional mediating variable

Söderlund et al. (2017) argued that employee humor usage can influence not only perceived relevance but also customer affect (and thus that affect can be an additional mediator of the employee humor-customer satisfaction link). In their study, however, employee joke-telling 
versus no employee joke-telling conditions did not produce different levels of affect. One reason may be that their study comprised a setting in which employee jokes were embedded in quite extensive conversational non-humorous content. And when a relatively large share of non-humorous content demands attention and comprehension, the effects of humor on affect are likely to be attenuated. Indeed, the common finding that humor in ads produces positive affect should be seen in the light of most humor ads comprising little other content than humor itself (Spotts et al., 1997). This calls for a re-examination of the affective impact of employee humor use in settings that are more humor-dominant. In the present case, we assessed this in two ways: in Study 1, the employee-customer conversation was short, and in Study 2 employee humor appeared at several points. Both these situations, we believe, would make humor more salient vis-à-vis other conversational content, which facilitates an impact of employee humor use on customer affect. The theoretical arguments regarding this follow below.

When stimuli are humor-charged, positive affect can occur as an immediate and "precognitive” reaction (Bryant et al., 1981; Lyttle, 2001; Robert and Wilbanks, 2012; Romero and Cruthirds, 2006). Indeed, a frequent finding in advertising studies is that humor enhances positive affect (Eisend, 2009; Eisend, 2011; Lee and Mason, 1999; Moran and Massam, 1999; Skalski et al., 2009). Similarly, humor has been shown to decrease state anxiety and enhance mood (Szabo, 2003). Then, in the next step of consumers’ information processing activities, positive affect can positively influence evaluations of messages and senders (Eisend, 2011). Thus affect may mediate the impact of employee joke-telling on customer satisfaction. However, affect may occur as a mediator also later in this causal chain, because perceived relevance can have a positive influence on affect (Ang et al., 2007). One main reason is that a relevant message is likely to enhance processing fluency - and processing fluency has been shown to have a positive impact on affect (Reber et al., 1998).

Regardless of when affect occurs, it can be assumed to influence overall evaluations in terms of an affect-as-information mechanism (Forgas, 1995). This influence, however, can work in opposing directions in a service encounter context. On the one hand, if employee humor usage increases "pre-cognitive” positive affect, one would expect a positive influence on customer satisfaction. This would be consonant with several studies showing that positive affect has a positive influence on customer satisfaction (e.g., Erevelles, 1998; Oliver, 1993). On the other hand, however, if humor attenuates perceived relevance (i.e., H1) and thereby reduces positive affect, one would expect less customer satisfaction among customers who 
are exposed to employee humor. In addition, given that incongruity can produce negative affect, because incongruent stimuli demand more elaborated processing (Garbarino and Edell, 1997), we would again expect a negative impact on customer satisfaction.

In sum, when employee humor is allowed to have a salient role in relation to other conversational content in a service encounter, we assume that (a) humor impacts customer affect and (b) affect can have a mediating role in the relation between employee humor usage and customer satisfaction. Since employee humor usage can result in both positive and negative affect, however, the net outcome in relation to customer satisfaction must be settled in empirical terms. Here, we hypothesize the following in order to assess of the role of affect in service encounters with employee joke-telling:

H4: The impact of employee joke-telling on customer satisfaction is mediated by customer affect

\section{Study 1}

A between-subjects experiment was conducted to assess Hypotheses 1-4. The experimental design comprised an employee joke-telling factor with two levels (no joke-telling vs. joketelling), and we used a text-based role-play scenario approach for the manipulations.

\subsection{Stimulus development, participants and data collection}

In the scenario (see Appendix 1), the participants were asked to assume the role of a guest who was checking in at a hotel. This involved a short conversation with an employee at the reception desk; this employee provided some hotel-related information to the guest and answered a couple of the guest's questions. In the no joke-telling condition, there was no joke-telling by the employee; in the joke-telling condition, the employee told one hotelrelated joke, in terms of a short story, in the midst of the conversation. The congruency between the joke (which was related to what the guest was asking about) and the other conversational (and hotel-related) elements was assumed to be relatively high - a setting which in general seems to foster positive effects of humor (van Dolen et al., 2008; Fugate, 1998; Scott et al., 1990). This setting, then, would allow for a relatively strong test of predictions that humor usage can reduce customer satisfaction. Everything else that happened in the scenarios was kept constant. The participants $\left(n=80, M_{\text {age }}=24.36,28\right.$ men and 52 
women), which we recruited from business administration courses, were randomly allocated to one of two scenario versions. After having read the scenario text, they were asked to respond to a set of questionnaire items.

\subsection{Measures}

Perceived relevance was measured as a response to a question about what the hotel employee said to the guest. Four adjective pairs developed by Söderlund et al. (2017) were used in the present study: "Few things were relevant-Many things were relevant", "Weak connection to what I wanted to know-Strong connection to what I wanted to know”, "Low level of fit with the situation-High level of fit with the situation", and "Certain parts of the content were not appropriate-Most parts of the content were appropriate”. Similar items have been used in an advertising context by, for example, Lee and Mason (1999). The items were scored on a 10point scale (a low score thus indicates a low level of perceived relevance). Cronbach's alpha for this scale was .91, and we used the average response to the four items as a measure of perceived relevance. To assess the validity of this scale we assumed, first, that incongruity would be negatively associated with perceived relevance. Therefore, we used a single-item measure to assess incongruity of the receptionist's behavior ("standard behavior-unexpected behavior”, scored on a 10-point scale) and we computed the zero-order correlation between the responses to this item and the perceived relevance item. The result was a negative and significant correlation $(r=-.40, p<.01)$. Second, we used a single-item measure of how easy it was to understand the employee; it was scored on a scale ranging from 1 (difficult) to 10 (easy). The response to this item was positively and significantly associated with the response to the perceived relevance scale $(r=.75, p<.01)$. Given the assumptions that incongruity can reduce perceived relevance, and that perceived relevance facilitates understanding of messages (Heckler and Childers, 1992), our relevance measure thus behaved as expected from a nomological validity point of view.

To measure customer satisfaction, we used Fornell's (1992) three satisfaction items, which have been employed in several national satisfaction barometers (Johnson et al., 2001). The items were formulated as follows in our hotel setting: "How satisfied or dissatisfied are you with this hotel?” ( 1 = very dissatisfied, 10 = very satisfied), “To what extent does this hotel meet your expectations?" ( 1 = not at all, $10=$ totally), and "Imagine a hotel that is perfect in every respect. How near or far from this ideal do you find this hotel?” ( 1 = very far from, 10 = cannot get any closer). Cronbach's alpha for this scale was .92, and we used the average response to the three items as a satisfaction measure. As a validity check, we included a 
single-item measure of the intention to engage in word-of-mouth regarding the hotel (scored on a 10-point scale). It was significantly and positively associated with customer satisfaction $(r=.68, p<.01)$. The satisfaction measure thus behaved as expected in relation to many previous studies resulting in a positive association between customer satisfaction and wordof-mouth.

Affect was measured in terms of valence (i.e., pleasantness). We used the question "How would you describe your feelings at this point in your hotel stay?” (i.e., immediately after having checked in), followed by the items "negative emotions-positive emotions", "sadjoyful”, and “bad mood-good mood”. Cronbach’s alpha for this scale was .92. Also in this case we used the average response to the three items as a measure in the analysis.

As a manipulation check for being exposed to joke-telling versus no joke-telling, and in the very end of the questionnaire, the participants were given the statement "The employee told a joke in the conversation” to be scored on a scale ranging from 1 (do not agree at all) to 10 (agree completely). It should be noted that the joke in our joke-telling condition was intended to be fun in the context in which it was told, so to assess this aspect the participants were asked to rate the employee in terms of the adjective pair "boring-fun" on a 10-point scale. This item was embedded in set of filler items regarding other characteristics of the employee.

\subsection{Analysis and results}

The responses to the manipulation check item ("The employee told a joke in the conversation") reached a higher level in the joke-telling condition $(M=6.88)$ than in the no joke-telling condition $(M=2.59)$. This difference was significant $(t=8.30, p<.01)$, thus suggesting that the manipulation behaved as intended. Moreover, the employee was rated as being more fun in in the joke-telling condition $(M=7.07)$ than in the no joke-telling condition $(M=5.90)$. This difference was significant $(t=2.89, p<.01)$, indicating that the selected joke was fun in the context in which it was told.

As for the $\mathrm{H} 1$ test, the level of perceived relevance was lower in the joke-telling condition ( $M$ $=5.40)$ than in the no joke-telling condition $(M=8.00)$. This difference was significant $(t=$ 7.05, $p<.01)$. H1 was thus supported. Moreover, customer satisfaction was lower in the joketelling condition $(M=6.79)$ than in the no joke-telling condition $(M=7.50)$. This difference was significant $(t=2.11, p<.05)$, which means that $\mathrm{H} 2$ was supported. 
For H3, our first mediation hypothesis, we used the Preacher and Hayes bootstrapping approach (Zhao et al., 2010). In our analysis, the independent variable was employee joketelling (scored as 1 if there was no joke-telling and 2 if there was joke-telling). The mediating variable was perceived relevance, and the dependent variable was customer satisfaction. The zero-order correlations between these variables were as follows: $r=-.62(p<.01)$ for the employee joke-telling-perceived relevance association; $r=.65(p<.01)$ for the relevancesatisfaction association; and $r=-.23(p<.01)$ for the joke-telling-satisfaction association. A mediation assessment with Hayes' Model 4 indicated a significant indirect effect from the bootstrap analysis of -1.68 (5000 bootstrap samples, 95\% CI limits -2.30 and -1.06), thus suggesting that the (negative) effect of employee joke-telling on customer satisfaction was mediated by perceived relevance. H3 was thus supported. The direct effect of employee joke-telling on satisfaction (-0.89), however, was also significant $(p<.01)$, suggesting that complementary mediation was at hand. That is to say, perceived relevance indeed mediated the employee joke-telling-satisfaction association, yet the significant direct impact suggests that also other mediating variables (such as affect) may have influenced customer satisfaction.

Turning to H4, regarding affect as an additional mediator, it should first be noticed that the joke-telling condition produced a lower level of positive affect $(M=7.11)$ than the no joketelling condition $(M=7.93)$. This difference was significant $(t=2.68, p<.01)$. Thus, joketelling by the employee reduced positive affect. To assess the mediation aspect, we followed the same approach as for the H3 test (yet in this case affect was the mediating variable). An assessment with Hayes’ Model 4 indicated a significant indirect effect from the bootstrap analysis of -0.65 (5000 bootstrap samples, 95\% CI limits -1.23 and -0.19), thus suggesting that the (negative) effect of employee joke-telling on customer satisfaction was mediated by affect. The direct effect of employee joke-telling on satisfaction $(-0.07)$ was not significant $(p=.79)$. H4 was thus supported by this analysis.

Our reasoning regarding $\mathrm{H} 3$ and $\mathrm{H} 4$, however, implies that both perceived relevance and affect can be involved in the same mediation chain. And theoretical arguments can be used to support both a chain of the type (1) joke-telling - affect - relevance - satisfaction and (2) joke-telling - relevance - affect - satisfaction. To examine this further, we assessed chain (1) with the Hayes procedure for analysis of serial mediation (Model 6). This analysis showed that there was a significant indirect effect $(-0.70)$ with both mediators in place (5000 
bootstrap samples, 95\% CI limits -1.21 and -0.36). The same analysis of chain (2) also indicated a significant indirect effect ( -0.21$)$ with both mediators (5000 bootstrap samples, $95 \%$ CI limits - 0.46 and -0.06). Both chains thus fit with our data, yet the relatively stronger indirect effect in chain (1) versus chain (2) can perhaps be seen as an indicator of chain (1) as a better model of mediation. In any event, this examination provides further support for both $\mathrm{H} 3$ and $\mathrm{H} 4$.

\subsection{Discussion}

Study 1 showed that employee joke-telling in the service encounter reduced customer satisfaction. The results also indicated that employee joke-telling reduced both perceived relevance and positive affect, and that both variables mediated the link between joke-telling and satisfaction. These results were obtained in a setting in which the service encounter was characterized by a relatively short customer-employee conversation in which there was relatively little other information for the customer to attend to - and there was no particular theme in what the employee said. This, we assume, would (a) reduce the disruptive potential of jokes with respect to perceived relevance and (b) enhance the potential for a positive impact on customer affect. Yet the joke in Study 1 was still able to reduce satisfaction compared to the no-joke condition.

However, as in Söderlund et al. (2017), the joke-telling in Study 1 comprised a story, and this story appeared as a distinct and bounded speech act in the midst of a conversation comprising also other elements. Given that the story format can be particularly absorbing, and given that stories are likely to stand out as distinct conversational element, other forms of employee humor usage - which are better integrated in a conversation - may produce different effects. Indeed, several authors have suggested that different types of humor are likely to have different consequences (Bryant et al., 1980; Lyttle, 2001).

Moreover, the Study 1 setting (and Söderlund et al.'s settings) comprised a traditional dyadic service encounter in which only one employee and one customer were present. Many service encounters, however, involve several customers who consume a service as a (temporary) group. This invites the possibility that employee humor usage can have effects on grouprelated variables (which in the next step can have a positive influence on customer satisfaction). One such variable is perceived team spirit, defined here as a sense of belongingness to the group and sharing a common goal (Jaworski and Kohli, 1993; Kohli and 
Jaworski, 1990). Several authors have argued that humor usage in a work group setting can enhance team spirit perceptions (Cooper, 2008; Duncan, 1982; Duncan and Feisal, 2009; Dwyer, 1991; Morkes et al., 1999; Robert and Wilbanks, 2012; Romero and Cruthirds, 2006). We assume that this can happen also in a (temporary) group of customers, which can be seen as an ad-hoc team when they consume the same service together. One reason is that humor usage can be self-revealing, which is likely to facilitate bonding between group members (Robert and Wilbanks, 2012). Indeed, in evolutionary terms, humor can be seen as a social grooming activity, and in this sense it can enhance affectional ties between group members (Eisend, forthcoming). Another reason is that humor usage can signal intra-group similarities and inter-group differences (Cooper, 2008; Dwyer, 1991). Given a service that is consumed by a group of customers who interact with the same employee, the following is therefore hypothesized:

H5: Employee joke-telling in interactions with a group of customers enhances the customer's perceptions of team spirit

A second group-related variable is perceived employee support, which we define in terms of the employee being aware of the customers' needs and is responsive to them. This notion of support vis-à-vis a group is typically used in work group settings and with reference to the group leader (Jones and James, 1979). Again in a work group context, several authors have claimed that humor can enhance support activities, such as coaching and counseling, particularly in terms of support from a mentor to a protégé. For example, humor can be a way to subtly point out mistakes in socially acceptable ways and to suggest alternative approaches to solving problems, which could reduce defensiveness and increase the likelihood of behavioral change (Robert and Wilbanks, 2012; Wood et al., 2011). In addition, humor can boost support activities by reducing social distance between leaders and followers (Dwyer, 1991; Romero and Cruthirds, 2006) and by improving followers' views of the leader's relationship-orientation (Cooper, 2008). Given this, we assume that humor usage by an employee in a service encounter with coaching content and comprising a group of customers can signal that the employee has support intentions. To assess this, the following is hypothesized:

H6: Employee joke-telling in interactions with a group of customers enhances the customer's perceptions of employee support 
Perceived team spirit and perceived employee support, we assume, are relevant particularly in a group service encounter setting involving (a) the transfer of knowledge from the employee to the customers and (b) co-creation in which both the employee and the customers contribute to the production of a service. Moreover, in this setting, we assume that both perceived team spirit and perceived employee support would have positive effects on customer satisfaction, because such variables have been shown to impact job satisfaction in work group settings (e.g., Carless and De Paola, 2000; Chou et al., 2002; Werner and Lester, 2001). If such effects indeed materialize as a result of employee humor usage also in ad-hoc teams of customers who consume the same service together, it thus means that the disruptive impact of humor usage on perceived relevance (i.e., H2) can be offset by positive effects produced by the group-level variables. To assess this, the following is hypothesized with respect to service encounters involving the employee and a group of customers:

H7: Perceived team spirit and perceived employee support are positively associated with customer satisfaction

To examine these issues, we conducted a second study in which the setting involved a service consumed by a (temporary) group of customers. In this study employee joking comprised short comments and remarks with the intention of being fun; these comments appeared here and there in the conversation (rather than at one particular point in the conversation as in the story case in Study 1). The second study also included measures of perceived team spirit and perceived employee support. The purpose of this second study was to re-test H1-H4 from Study 1 in a different service setting and with another type of employee humor, and to examine the consequences of employee joking on two group-related variables ( $\mathrm{H} 5$ and $\mathrm{H} 6$ ) that we assume are positively related to customer satisfaction (H7).

\section{Study 2}

A between-subjects experiment was conducted to test Hypotheses 1-7. The experimental design comprised an employee joke factor with two levels (no joke-telling vs. joke-telling), and a text-based role-play scenario approach was used for the manipulations.

4.1 Stimulus development, participants, and data collection 
In the scenario (Appendix 2), the participants were asked to assume the role of a customer who attends a gym class in which an instructor provides information about what to do (and what the benefits are of various activities). This type of context was selected because some authors have suggested that humor in an education context would make lessons easier to grasp, facilitate attention (Bryant et al., 1980; Bryant et al., 1981), and enhance participants' learning (Garner, 2006). A service setting involving interaction with an instructor, we assumed, would therefore provide a relatively strong test of the possibility that humor usage can decrease perceived relevance.

In the no joke-telling condition, there was no joke-telling by the instructor; in the joke-telling condition, the instructor delivered five short comments here and there during the class with the intention of being fun. Morkes et al. (1999) have used a similar humor manipulation. The jokes in the present study were partly inspired by a YouTube video with Amy Schumer, an American stand-up comedian, who played the role of gym instructor in that video. Everything else that happened in the two scenarios was kept constant. The participants ( $n=88, M_{\text {age }}=$ 20.86; 40 men and 45 women; three participants did not report their gender), which we recruited from business administration courses, were randomly allocated to one of two scenario versions. After having read the scenario text, they were asked to respond to a set of questionnaire items.

\subsection{Measures}

Perceived relevance (alpha $=.83$ ) was measured with the same items as in Study 1. We also used the same single-item measures as in Study 1 to assess (a) the incongruity of the instructor's behavior and (b) comprehension of what the instructor said. The responses to these two items correlated significantly with the perceived relevance measure $(r=-.18, p<$ $.10 ; r=.33, p<.01$ ), indicating that the perceived relevance measure behaved as expected form a nomological validity point of view. Customer satisfaction (alpha $=.83$ ) and positive affect (alpha $=.91$ ) were measured with the same 10-point scale items as in Study 1. Perceived team spirit was measured with the items "The instructor built a sense of shared purpose", "The instructor created a 'we-are-all-in-the-same-team' feeling during the class", "The instructor made me feel like all of us in the class were 'in it together", and "The 
instructor emphasized a common goal for the participants" to be scored on scales ranging from 1 (do not agree at all) to 10 (agree completely). A similar measure was used by Jaworski and Kohli (1993). In our case, Cronbach's alpha was .90. Perceptions of employee support was measured with three items: "The instructor was genuinely concerned about the needs of the participants", "The instructor cared about the participants", and "The instructor wanted to improve the life of the participants", scored on scales with 1 (do not agree at all) and 10 (agree completely) as endpoints (alpha $=.77)$. Similar items, but in a work group context and with respect to the group leader, have been used by Jones and James (1979).

As a manipulation check the participants were given the statement "The instructor told jokes during the class” to be scored on a scale ranging from 1 (do not agree at all) to 10 (agree completely). As a further manipulation check, and to evaluate the nature of the jokes in the joke-telling condition in the same way as in Study 1, the participants were asked to assess the instructor in terms of the adjective pair "boring-fun" on a 10-point scale (embedded in a set of filler items regarding other instructor characteristics).

\subsection{Analysis and results}

The responses to the first manipulation check item ("The instructor told jokes during the class”) reached a higher level in the joke-telling condition $(M=7.62)$ than in the no joketelling condition $(M=3.02)$. This difference was significant $(t=10.02, p<.01)$. Moreover, the responses to the second check item about how fun the instructor was perceived to be reached a higher level in the joke-telling condition $(M=7.54)$ than in the no joke-telling condition $(M=6.25)$. This difference was significant $(t=3.18, p<.01)$. This thus indicates that the manipulation behaved as intended (and that the instructor's jokes in the joke condition were perceived as fun in the context in which they were told).

The level of perceived relevance was lower in the joke-telling condition $(M=6.14)$ than in the no joke-telling condition ( $M=7.25)$. This difference was significant $(t=3.40, p<.01)$; H1 was thus supported. Moreover, customer satisfaction was lower in the joke-telling condition $(M=6.25)$ than in the no joke-telling condition $(M=7.03)$. This difference was significant $(t=2.27, p<.05)$, which means that $\mathrm{H} 2$ was supported.

To test H3, we used the same bootstrapping approach as in Study 1 (Zhao et al., 2010). The independent variable was employee joke-telling (scored as 1 if there was no joke-telling and 2 
if there was joke-telling). The mediating variable was perceived relevance; customer satisfaction was the dependent variable. The zero-order correlations between these variables were as follows: $r=-.34(p<.01)$ for the employee joke-telling-perceived relevance association; $r=.61(p<.01)$ for the relevance-satisfaction association; and $r=-.24(p<.01)$ for the joke-telling-satisfaction association. A mediation assessment with Hayes' Model 4 indicated a significant indirect effect from the bootstrap analysis of -.68 (5000 bootstrap samples, 95\% CI limits -1.29 and -0.24), thus suggesting that the negative effect of employee joke-telling on customer satisfaction was mediated by perceived relevance. The direct effect of employee joke-telling on satisfaction $(-0.11)$ was not significant $(p=.73)$. H3 was thus supported.

With respect to $\mathrm{H} 4$, regarding affect as a mediator, the joke-telling condition produced a lower level of positive affect $(M=6.98)$ than the no joke-telling condition $(M=7.83)$. This difference was significant $(t=2.40, p<.05)$. Thus, employee joke-telling reduced positive affect. These results are similar to Study 1 . To assess the potential for mediation with respect to the joke-telling-affect-satisfaction chain, we used Hayes’ Model 4. It indicated a significant indirect effect from the bootstrap analysis of -0.53 (5000 bootstrap samples, 95\% CI limits -1.08 and -0.11), which suggests that the (negative) effect of employee joke-telling on customer satisfaction was mediated by affect. The direct effect of employee joke-telling on satisfaction $(-0.25)$ was not significant $(p=.37)$. H4 was thus supported.

Again, our reasoning regarding $\mathrm{H} 3$ and $\mathrm{H} 4$ implies that both perceived relevance and affect can be involved in the same mediation chain. To examine this, we first assessed the joketelling-affect-relevance-satisfaction chain. The Hayes procedure (Model 6) showed that there was a significant indirect effect (-0.13) with both mediators in place (5000 bootstrap samples, 95\% CI limits -0.37 and -0.03). Second, we assessed the joke-telling-relevanceaffect-satisfaction chain, again with Model 6 in the Hayes procedure. This analysis indicated a significant indirect effect (-0.26) with both mediators (5000 bootstrap samples, 95\% CI limits -0.58 and -0.09). Thus, as in Study 1, both chains fit with our data. Yet in the Study 2 analysis, the indirect effect in the second chain was stronger than the indirect effect in the first chain. In any event, this examination provides further support for both H3 and H4.

As for the team spirit hypothesis (H5), employee joke-telling produced a higher level of perceived team spirit $(M=6.74)$ than the no joke-telling condition $(M=6.21)$. However, this difference was not significant $(t=1.32, p=.19)$. With respect to the employee support 
hypothesis (H6), the levels in the two conditions were very similar ( $M=5.89$ for no joketelling; $M=5.88$ for joke-telling). This difference was not significant $(t=0.03, p=.97)$. Thus neither H5 nor H6 were supported. Nevertheless, both group-related variables were positively and significantly associated with customer satisfaction. For perceived team spirit, $r$ was 0.38 $(p<.01)$; for perceived employee support, $r$ was $0.37(p<.01)$. This provides support for H7. In other words, even though employee humor usage did not affect these variables, the results indicate that they can have a satisfaction-boosting potential in a service setting in which the customers represent a (temporary) group.

\section{General discussion}

\subsection{Summary of main results}

The main result was that employee joke-telling in the service encounter reduced customer satisfaction. This happened both when a joke appeared as a story in a short conversation (Study 1), and when several jokes appeared as comments intended to be fun and were made here and there in a conversation (Study 2). These characteristics were assumed to be able to reduce the disruptive potential of jokes with respect to perceived relevance, but perceived relevance was attenuated anyway. Moreover, the results indicate that employee joke-telling reduced not only perceived relevance but also positive affect, and both these variables mediated the link between employee joke-telling and customer satisfaction (Study 1 and Study 2).

\subsection{Contributions}

The present results replicate the Söderlund et al. (2017) findings regarding a negative association between employee humor usage in the service encounter and customer satisfaction. The present studies also extend the Söderlund et al. (2017) findings by examining other service settings, other conversational contexts in which jokes appear, and other types of jokes. This contributes to the literature on service encounters, which to date has showed that many employee-related characteristics and behaviors have an impact on customer satisfaction. So far, however, the impact of employee humor usage has received little attention in service encounter research, despite the fact that it has been observed that employees use humor in this setting (Gilliam et al., 2014; Gwinner et al., 1998; Locke, 1996; Pearce, 2009; Price et al., 1995). A specific contribution to this literature is the replication and extension of the Söderlund et al. (2017) 
finding regarding perceived relevance as a mediating variable, because perceived relevance (and other characteristics of the employee's message) have rarely been examined in the service encounter literature. This should be seen as an unfortunate shortcoming in the light of several authors arguing that what the employee says to the customer in a service encounter is crucial for customer satisfaction (e.g., Grewal et al., 2002; Haas and Kenning, 2014; Webster and Sundaram, 2009).

Moreover, the results contribute to the general literature on the effects of humor in marketing settings, a literature that is dominated by advertising studies in which positive effects of humor are prevalent. Mixed and negative results of humor, however, have been reported in previous advertising studies (e.g., Oikarinen and Söderlund, 2016), thus suggesting that humor is not universally superior to non-humor in a communication context (Chattopadhyay and Basu, 1990). This should be seen in the light of a research stream asking when humor is effective (Cline and Kellaris, 1999; Smith 1993). The present results contribute to this stream by adding evidence that humor usage can have negative effects on the receiver, particularly in terms of perceived relevance as a mediating variable. This is in contrast to authors who have claimed that humorous messages are better understood (Wood et al., 2011) and that they can enhance learning (Garner, 2006; Wanzer and Frymier, 1999).

The combined results in Söderlund et al. (2017) and the present study regarding perceived relevance also indicate that the relation between elements within a verbal message (in our case: humor vs. other content) calls for further attention by researchers. Yet many existing studies of the interplay between various message elements have focused on the relation between a verbal message and other elements (e.g., pictures in an ad; Houston et al., 1987). Seen in the light of this, and given consumer sensitivity to relevancy aspects, research involving verbal messages to consumers (e.g., studies of employees' statements in service encounters, in-store signage, and copy in ads) would benefit if more attention is devoted to the message itself in terms of how well various elements are perceived to be integrated.

\subsection{Managerial implications}

Several authors encourage managers to use humor in organizational settings (e.g., Rizzo et al., 1999). Many firms have also made attempts to produce humor in the organization in a systematic way (Redman and Mathews, 2002; Wood et al., 2007), and some firms, such as Southwest Airlines, also encourage employee usage of humor in service encounters (Redman 
and Mathews, 2002). The findings in the present empirical studies, and Söderlund et al.'s (2017) findings, however, point in the same way for various joke types and service settings: employee joke-telling in the service encounter reduces customer satisfaction. Before these findings are qualified by further research, our recommendation is therefore that employees should avoid joke-telling in their conversations with customers if the objective is to boost customer satisfaction.

However, our empirical results indicate that perceived relevance was positively and significantly associated with customer satisfaction ( $r=0.65$ in Study 1, $r=0.61$ in Study 2). Moreover, positive associations in relation to customer satisfaction were found also for perceived team spirit ( $r=0.38$ in Study 2$)$ and perceived employee support ( $r=0.37$ in Study 2). Although employee joke-telling did not enhance the levels of these three variables, other activities may indeed do so. The exploration of what these activities are - and how to encourage frontline employees to engage in them - calls for managerial attention in firms that wish to enhance customer satisfaction. For example, with respect to relevance norms in conversations, it has been suggested that the relevant sender must understand the goals of the receiver, provide inputs so that these goals are met, and deliver content that is interesting for the receiver (Skowronski and Walker, 2004). These are thus specific aspects that could be examined further for those who are concerned about relevance in conversations. Similarly, the organizational literature provides many clues regarding factors that can boost perceived team spirit and perceived support in work groups, and such clues may be helpful in developing employee behavior in service encounters comprising ad-hoc groups of customers.

\subsection{Limitations and suggestions for further research}

We examined two types of employee joke-telling in the present studies, namely joke-telling in terms of a story (Study 1) and short comments intended to be fun (2). Yet there are also other types of jokes, such as wordplay, irony, and personal narratives (Boxer and CortésConde, 1997; Dynel, 2009; Norrick, 1994; Norrick, 2003), and further research should make attempts to systematically examine if different types of jokes can have different effects when they are delivered by an employee in a service encounter. Similarly, there are different forms of humor, such as social humor, repressed humor, and self-enhancing humor (cf. Wood et al., 2007) that may materialize in terms of jokes. Such forms need to be assessed before the final word is said on employee joke-telling and its impact in service encounters. 
Further research on the impact of employee use of jokes in the service encounter should also make attempts to examine additional mediation issues. We assumed that affect can occur in different stages of a process beginning with employee usage of humor and ending with customer satisfaction, but to examine this further additional research is needed in terms of measuring affect at different points in the process. Further research should also explicitly examine variables such as perceived incongruity, comprehension, and processing fluency as potential mediators. In addition, humor usage by an employee may result in inferences about the employee. Given that the employee is the organization from the customer's point of view (Bitner et al., 1990; Surprenant and Solomon, 1987), such inferences can have an impact on customer satisfaction. For example, a person using humor may be perceived as less trustworthy and less intelligent (Bressler and Balshine, 2006). And a service encounter comprising an employee who is perceived as low in trust and intelligence may have a negative influence on customer satisfaction. Moreover, an employee signaling happiness can have a positive influence on receiver responses (Söderlund and Sagfossen, 2017), and it is possible that humor usage can signal employee happiness. Thus customer perceptions of the employee's affective state may be an additional mediator to include in further examinations. With respect to potentially moderating variables, our two studies represent attempts to simulate face-to-face interactions between employees and customers in service encounters. Such face-to-face interactions still dominate in many sectors, particularly in retailing (Bronnenberg and Ellickson, 2015). Various form of electronically-based encounters, however, can be expected to increase. Further studies should therefore assess the potential for employee joking to influence customer reactions in computer-based employee-customer interactions. It should also be noted that all our manipulations (also the satisfaction-reducing joke-telling conditions) resulted in relatively high levels of customer satisfaction, because in all conditions overall employee performance was relatively good as opposed to poor. Further research should therefore explore the impact of joke-telling when employee performance is poor. For example, it is possible that joke-telling can signal employee concern and thereby reduce the negative impact of other (and poorly performed) employee activities. It is of course also possible that joke-telling under the condition of poor performance would add even more fuel to customers' negative reactions. Moreover, our manipulations depicted the customer and the service employee as being unfamiliar with each other (thus they had no prior relationship history). However, if the interacting parties are more familiar with each other, as a result of several service encounters over time, humor usage may produce different (and positive) effects on the receiver. Bryant et al. (1980) and Wanzer and Frymier (1999), for example, have shown that teachers' use of humor in class can produce positive effects on 
students' ratings of teachers and on students' learning. Similarly, managers' use of humor has been shown to have several positive effects on organizational members (Decker and Rotondo, 2001). This thus means that employee joke-telling in the context of ongoing customeremployee relations needs to be examined. In addition, Bryant et al.'s (1980) results suggest that the sender's personal characteristics seem to influence the effectiveness of humor, in the sense that the positive humor usage effects in their study were obtained for male but not female teachers. The potential for different effects of humor usage on the receiver when the sender is male or female has been underlined by several other authors (e.g., Eisend, forthcoming; Wood et al., 2007). This, then, is an additional aspect that needs to be examined in a service encounter context. Further research should also consider the moderating potential of receiver characteristics, such as, for example, need for cognition (Cline and Kellaris, 1999), humor orientation (Rizzo et al., 1999), humor appreciation (Duncan et al. 1990), need for humor (Cline et al., 2003), and gender (Duncan, 1982; Duncan et al. 1990; Eisend, forthcoming; Wood et al., 2007).

Finally, it should be underscored that even though the present study provided evidence for employee joke-telling to have a negative impact on customer satisfaction, other response variables may be subject to a positive impact. For example, humor-comprising messages have been found to be recalled better than messages without humor (Krishnan and Chakravarti, 2003), probably because the incongruency involved in humor demands more elaborate processing (cf. Houston et al., 1987). Humorous messages may also encourage more word-ofmouth activity than non-humorous messages (Eisend, forthcoming; Oikarinen and Söderlund, 2016), and this aspect needs to be considered in times when information sharing between customers is considered important by many firms. 


\section{Appendix 1: The hotel scenario*}

You have booked a two-night stay in a hotel for a trip to the capital of a country that you have not visited before. When you arrive at the hotel, quite late in the evening, you go to the reception. Some years ago, on another trip, you arrived late to a hotel - and that hotel had simply cancelled your reservation without saying anything. You hope that this will not happen again, because you do not feel like looking for hotels in a foreign city at this late hour.

"Welcome! What can I do for you?" asks the employee at the reception desk.

"I have made a reservation for two nights in this hotel, so I would like to check-in", you say.

"OK, may I see your passport, please", says the employee.

You hand over your passport to the employee, who turns to the computer and begins to search for your reservation.

"OK, we indeed have a nice room for you, for two nights. Would you perhaps consider Staying longer; we have some rooms available also for the following nights?" says the employee.

"Two nights are enough", you say.

"OK, two nights! Have you been to this hotel before?" asks the employee.

"No", you say.

"Well, here is your key; your room is on the fourth floor, please use the elevators to the right",

says the employee and points to the right in the lobby.

The lobby looks inviting; it actually looks more like someone's personal living room than a hotel lobby. Nice art on the walls, even sculptures, and comfortable-looking chairs and sofas in which some guests are seated. There is also an entrance to a bar, and you see that quite a number of guests are in there.

"When does the bar close?" you ask. 
"You know, some weeks ago one of our guests asked me when our bar opens. I was here in the reception when he called - at 3 am. I said that the bar opens at noon. About one hour later, the guest called again and asked when the bar opens. Now he sounded a bit drunk. Again, I said it opens at noon. After another hour, he called again and asked when the bar opens. I think he was more drunk this time. I said that the bar opens at noon, and that I could have room service send something up to the guest if needed. Then the guest said 'No, I don't want to get in...I want to get out! Well, seriously, the bar closes only when there are no more clients! So you do have time to go there", says the employee.

"And when is the breakfast served?" you ask.

"Between 06.30 and 10.00. Make sure you bring your room key to the breakfast restaurant, it is on the second floor", says the employee.

You thank the employee and you go to the elevator. The first thing you want now is to look at your room and to get rid of your bag.

*The part in bold was used for the joke-telling condition.

\section{Appendix 2: The gym class scenario*}

A friend has suggested that you should go together to a gym class; this friend has received a "bring-a-friend-offer" so you can come along for free. You have accepted to do this.

In total, some 15-20 people have showed up for this core class, which is supposed to have an abdominal focus. The instructor comes five minutes before the class and walks around among the participants and says "Hello!", "Welcome!", and "Nice that you could come!" to each participant. The instructor looks fit, but not in an exaggerated sense.

When it is time to begin, the instructor explains that today's class will deal with core exercises, and that it will be about 45 minutes long. There will be some 5-6 exercises with variations.

"What we'll do is exercises to build muscle and burn fat. A strong core prevents back problems, and the reason why we want to get rid of fat is not necessarily aesthetic; as you know, too much core fat is a potential health risk in the long run. Anyway, we devote too little time to our core when we exercise. This is sad, because the core is perhaps the most important part of our bodies. Everything else is connected to the core one way or another. So, are you ready?" asks the instructor.

The participants say that they are ready. First, there is some warming up.

"OK, let's get started! This is going to be tough! This is not an exercise class. It's a funeral - for our fat. And nobody's going to miss it!", says the instructor.

The class begins with V-sits with so-called Russian twists. The only part of your body that is in contact with the floor is your butt, you roll up, move arms and legs upwards - and add an upper body twist to the left or to the right in the final movement. 
"Do as many as you can, but hold back a little, we're doing 6 sets. This is really tough if you do it correctly. Yes, this a declaration of war on fat! And we're going to violate the Geneva Convention!" says the instructor.

The next exercise is Military sit-ups. You work in pairs, the lower part of your legs is locking your partner's legs and vice versa.

"I want you to do 40 of these. But again hold back a bit, were doing five sets", says the instructor.

Then it is time to do Classics. Arms crossed over the chest, the only thing that moves is your upper body. Legs bent, heels on the floor.

"I want you to do 50 of these. This time we'll do three sets. This builds strength in the core. Some instructors consider these outdated, but recent research shows that they are a really a good complement to the other things we do today. This is what it is, a complement, do not do only these when you work out on your own. For really good results in the long run, of course we need to think about what we eat as well. Avoid fat foods. You know what I eat for breakfast? I eat fat for breakfast!" says the instructor.

And then comes the Plank. Your lower arms and the toes touch the floor. Just hold it. Forever. This is tough. You are pretty exhausted now. You look at yourself in the mirror; you are really sweating.

"Yeah, look at yourself in the mirror. You know why gyms have mirrors? I do not really understand that - we already know what we look like, that's why we're here!" shouts the instructor.

There is only one more exercise to do.

"Look at me, lay on the back, no space between your back and the floor, fix the legs 90 degrees up, make sure the belly is flat. Your rib cage is down, hands behind your head, and move only the upper part of the body upwards. Inhale thorough the nose before you move, exhale through the mouth when you move. This is my favorite. You know when I began with it? I was in front of the mirror admiring my sixpack, but I felt it started to get warm so I had to put it back in the fridge. We'll do 50 of these. Five sets", says the instructor.

Finally, the class ends.

"Do not forget that the core needs special attention!" says the instructor. The instructor thanks all of you for coming and says goodbye.

*The five parts in bold were used for the joke-telling condition. For the no joke condition, part 1 was replaced with "This is an exercise class, not a vacation!", part 2 was deleted, part 3 was replaced with "I eat never eat anything with fat!", part 4 was replaced with "So that we can see if we make the correct moves!", and part 5 was deleted. 


\section{References}

Agarwal, R. and Karahanna, E. (2000), Time flies when you're having fun: Cognitive absorption and beliefs about information technology usage, MIS Quarterly, 24 (4), 665-694.

Alden, D.L. and Hoyer, W.D. (1993), An examination of cognitive factors related to humorousness in television advertising, Journal of Advertising, 22 (2), 29-37.

Ang, S.H., Lee, Y.H. and Leong, S.M. (2007), The ad creativity cube: Conceptualization and initial validation, Journal of the Academy of Marketing Science, 35 (2), 220-232.

Beal, D.J., Weiss, H.M., Barros, E. and MacDermid, S.M. (2005), An episodic process model of affective influences on performance, Journal of Applied Psychology, 90 (6), 1054-1068.

Bitner, M.J., Booms, B.H. and Tetreault, M.S. (1990), The service encounter: Diagnosing favorable and unfavorable incidents. Journal of Marketing, 54 (January), 71-84.

Boxer, D. and Cortés-Condes, F. (1997), From bonding to biting: Conversational joking and identity display, Journal of Pragmatics, 27 (3), 275-294.

Bressler, E.R and Balshine, S. (2006), The influence of humor on desirability, Evolution and Human Behavior, 27 (1), 29-39.

Bronnenberg, B.J. and Ellickson, P.B. (2015), Adolescence and the path to maturity in global retail. Journal of Economic Perspectives, 29 (4), 113-134.

Bryant, J., Comisky, P.W., Crane, J.S. and Zillmann, D. (1980), Relationship between college teachers' use of humor in the classroom and students' evaluations of their teachers, Journal of Educational Psychology, 72 (4), 511-519.

Bryant, J., Alan, D.B., Silberberg, R. and Elliott, S.M. (1981), Effects of humorous illustrations in college textbooks, Human Communication Research, 8 (1), 43-57. 
Busselle, R. and Bilandzic, H. (2009), Measuring narrative engagement, Media Psychology, 12 (4), 321-347.

Carless, S.A. and De Paola, C. (2000), The measurement of cohesion in work teams, Small Group Research, 31 (1), 71-88.

Chattopadhyay, A. and Basu, K. (1990), Humor in advertising: The moderating role of prior brand evaluation, Journal of Marketing Research, 27 (4), 466-476.

Chou, S.C., Boldy, D.P. and Lee, A.H. (2002), Staff satisfaction and its components in residential aged care, International Journal for Quality in Health Care, 14 (3), 207-217.

Cline, T.W. and Kellaris, J.J. (1999), The joint impact of humor and argument strength in a print advertising context: A case for weaker arguments, Psychology \& Marketing, 16 (1), 6986.

Cline, T.W., Altsech, M.B. and Kellaris, J.J. (2003), When does humor enhance or inhibit ad responses? The moderating role of the need for humor, Journal of Advertising, 32 (3), 31-45.

Cooper, C. (2008), Elucidating the bonds of workplace humor: A relational process model, Human Relations, 61 (8), 1087-1115.

Decker, W.H. and Rotondo, D.M. (2001), Relationships among gender, type of humor, and perceived leader effectiveness, Journal of Managerial Issues, 8 (4), 450-465.

De Keyzer, F., Dens, N. and De Pelsmacker, P. (2015), Is this for me? How consumers respond to personalized advertising on social network sites, Journal of Interactive Advertising, 15 (2), 124-134.

van Dolen, W.M., de Ruyter, K. and Streukens, S. (2008), The effect of humor in electronic service encounters, Journal of Economic Psychology, 29 (2), 160-179.

Dunbar, R.I.M., Launay, J., and Curry, O. (2016), The complexity of jokes is limited by cognitive constraints on mentalizing, Human Nature, 27 (2), 130-140.

Duncan, W.J. (1982), Humor in management: Prospects for administrative practice and research, Academy of Management Review, 7 (1), 136-142.

Duncan, W.J. and Feisal, J.P. (1989), No laughing matter: Patterns of humor in the workplace, Organizational Dynamics, 17 (4), 18-30.

Duncan, W.J., Smeltzer, L.R. and Leap, T.L. (1990), Humor and work: Applications of joking behavior to management, Journal of Management, 16 (2), 255-278.

Dwyer, T. (1991), Humor, power, and change in organizations, Human Relations, 44 (1), 119.

Dynel, M. (2009), Beyond a joke: Types of conversational humor, Language and Linguistics Compass, 3 (5), 1284-1299.

Easley, R.W., Madden, C.S. and Dunn, M.G. (2000), Conducting marketing science: The role of replication in the research process, Journal of Business Research, 48 (1), 83-92. 
Eisend, M. (2009), A meta-analysis of humor in advertising, Academy of Marketing Science Journal, 37 (2), 191-203.

Eisend, M. (2011), How humor in advertising works: A meta-analytic test of alternative models, Marketing Letters, 22 (2), 115-132.

Eisend, M. (forthcoming), Explaining the use and effects of humor in advertising: An evolutionary perspective, International Journal of Advertising.

Erevelles, S. (1998), The role of affect in marketing, Journal of Business Research, 42 (3), 199-215.

Evanschitzky, H., Baumgarth, C., Hubbard, R. and Armstrong, J.S. (2007), Replication research's disturbing trend, Journal of Business Research, 60 (4), 411-415.

Evanschitzky, H. and Armstrong, J.S. (2013), Research with in-built replications: Comment and further suggestions for replication research, Journal of Business Research, 66 (9), 14061408 .

Fornell, C. (1992), A national satisfaction barometer: The Swedish experience, Journal of Marketing, 56 (January), 6-21.

Forgas, J.P. (1995), Mood and judgment: The affect infusion model (AIM), Psychological Bulletin, 117 (1), 39-66.

Fugate, D.L. (1998), The advertising of services: What is an appropriate role for humor, The Journal of Services Marketing, 12 (6), 453-472.

Garbarino, E.C. and Edell, J.A. (1997), Cognitive effort, affect, and choice, Journal of Consumer Research, 24 (2), 147-158.

Garner, R.L. (2006), Humor in pedagogy: How ha-ha can lead to aha!, College Teaching, 54 (1), 177-180.

Gilliam, D.A., Flaherty, K.E. and Rayburn, S.W. (2014), The dimensions of storytelling by retail salespeople, The International Review of Retail, Distribution and Consumer Research, 24 (2), 231-241.

Green, M.C. and Brock, T.C. (2000), The role of transportation in the persuasiveness of public narratives, Journal of Personality and Social Psychology, 79 (5), 701-721.

Grewal, D., Levy, M. and Marshall, G.W. (2002), Personal selling in retail settings: How does the Internet and related technologies enable and limit successful selling?, Journal of Marketing Management, 18 (3-4), 301-316.

Gwinner, K.P., Gremler, D.D. and Bitner, M.J. (1998), Relational benefits in services industries: The customer's perspective, Journal of the Academy of Marketing Science, 26 (2), 101-114.

Haas, A. and Kenning, P. (2014), Utilitarian and hedonic motivators of shoppers' decision to consult with salespeople, Journal of Retailing, 90 (3), 428-441. 
Hansen, J., Strick, M., van Baaren, R.B., Hooghuis, M. and Wigboldus, D.H. (2009), Exploring memory for product names advertised with humour, Journal of Consumer Behaviour, 8 (2-3), 135-148.

Heckler, S.E. and Childers, T. L. (1992), The role of expectancy and relevancy in memory for verbal and visual information: What is incongruency?, Journal of Consumer Research, 18 (March), 475-492.

Houston, M.J., Childers, T. L. and Heckler, S.E. (1987), Picture-word consistency and the elaborative processing of advertisements, Journal of Marketing Research, 24 (November), 259-369.

Jaworski, B.J. and Kohli, A.K. (1993), Market orientation: Antecedents and consequences, Journal of Marketing, 57 (3), 53-70.

Johnson, M.D., Gustafsson, A., Andreassen, T.W., Lervik, L. and Cha, J. (2001), The evolution and future of national satisfaction index models, Journal of Economic Psychology, $22(2), 217-245$.

Jones, A.P. and James, L.R. (1979). Psychological climate: Dimensions and relationships of individual and aggregated work environment perceptions, Organizational Behavior and Human Performance, 23 (2), 201-250.

Ketrow, S.M. (1991), Nonverbal communication and client satisfaction in computer-assisted transactions, Management Communication Quarterly, 5 (2), 192-219.

Kohli, A.K. and Jaworski, B.J. (1990), Market orientation: The construct, research propositions, and managerial implications, Journal of Marketing, 54 (April), 1-18.

Krishnan, H.S. and Chakravarti, D. (2003), A process analysis of the effects of humorous advertising executions on brand claims memory, Journal of Consumer Psychology, 13 (3), $230-245$

van Kuilenburg, P., de Jong, M.D. and Van Rompay, T.J. (2011), That was funny, but what was the brand again? Humorous television commercials and brand linkage, International Journal of Advertising, 30 (5), 795-814.

Laczniak, R.N., Muehling, D.D. and Grossbart, S. (1989), Manipulating message involvement in advertising research, Journal of Advertising, 18 (2), 28-38.

Lee, Y.H. and Mason, C. (1999), Responses to information incongruency in advertising: The role of expectancy, relevancy, and humor, Journal of Consumer Research, 26 (September), 156-169.

Locke, K. (1996), A funny thing happened! The management of consumer emotions in service encounters, Organizational Science, 7 (1), 40-59.

Lyttle, J. (2001), The effectiveness of humor in persuasion: The case of business ethics training, The Journal of General Psychology, 128 (2), 206-216. 
Lyttle, J. (2007), The judicious use and management of humor in the workplace, Business Horizons, 50 (3), 239-245.

Meyer, J.C. (2000), Humor as a double-edged sword: Four functions of humor in communication. Communication Theory, 10 (3), 310-331.

Moran, C.C. and Massam, M.M. (1999), Differential influences of coping humor and humor bias on mood, Behavioral Medicine, 25 (Spring), 36-42.

Morkes, J., Kernal, H.K. and Nass, C. (1999), Effects of humor in task-oriented humancomputer interaction and computer-mediated communication: A direct test of SRCT theory, Human-Computer Interaction, 14 (4), 395-435.

Muehling, D.D. and McCann, M. (1993), Attitude toward the ad: A review, Journal of Current Issues and Research in Advertising, 15 (2), 25-58

Norrick, N.R. (1994), Involvement and joking in conversation, Journal of Pragmatics, 22 (34), 409-430.

Norrick, N.R. (2003), Issues in conversational joking, Journal of Pragmatics, 35 (9), 1333 1359.

Norrick, N.R. (2009), A theory of humor in interaction, Journal of Literary Theory, 3 (2), 261-283.

Oikarinen, E.L. and Söderlund, M. (2016). The effects of humour in online recruitment advertising. Australasian Marketing Journal, 24 (3), 180-186.

Oliver, R.L. (1993), Cognitive, affective, and attribute bases of the satisfaction response, Journal of Consumer Research, 20 (3), 418-430.

Pearce, P.L. (2009), Now that is funny: Humour in tourism settings, Annals of Tourism Research, 30 (4), 627-644.

Phillips, B.J. (2000), The impact of verbal anchoring on consumer response to image ads, Journal of Advertising, 24 (1), 15-24.

Price, L.L., Arnould, E.J. and Tierney, P. (1995), Going to extremes: Managing service encounters and assessing provider performance, Journal of Marketing, 59 (April), 83-97.

Reber, R., Winkielman, P. and Schwarz, N. (1998), Effects of perceptual fluency on affective judgments, Psychological Science, 9 (1), 45-48.

Redman, T. and Mathews, B.P. (2002), Managing services: Should we be having fun?, Service Industries Journal, 22 (3), 51-62.

Rizzo, B.J., Wanzer, M.B. and Booth-Butterfield, M. (1999), Individual differences in managers' use of humor. Subordinate perceptions of managers' humor, Communication Research Reports, 16 (4), 360-369.

Robert, C. and Wilbanks, J.E. (2012), The wheel model of humor: Humor events and affect in organizations, Human Relations, 65 (9), 1071-1099. 
Romero, E.J. and Cruthirds, K.W. (2006), The use of humor in the workplace, The Academy of Management Perspectives, 20 (2), 58-69.

Scott, C. Klein, D.M. and Bryant, J. (1990), Consumer response to humor in advertising: A series of field studies using behavioral observation, Journal of Consumer Research, 16 (March), 498-501.

Skalski, P., Tamborini, R., Glazer, E. and Smith, S. (2009), Effects of humor on presence and recall of persuasive messages, Communication Quarterly, 57(2), 136-153.

Skowronski, J.J. and Walker, W.R. (2004). How describing autobiographical events can affect autobiographical memories. Social Cognition, 22 (5), 555-590.

Smith, S.M. (1993), Does humor in advertising enhance systematic processing?, Advances in Consumer Research, Vol. 20, Association for Consumer Research, 155-158.

Speck, P.S. (1991), The humorous message taxonomy: A framework for the study of humorous ads, Current Issues and Research in Advertising, 13 (1-2), 1-44.

Spotts, H.E, Weinberger, M.G. and Parsons, A.L. (1997), Assessing the use of and impact of humor on advertising effectiveness: A contingency approach, Journal of Advertising, 24 (3), 17-32.

Sternhal, B. and Craig, C.S. (1973), Humor in advertising, Journal of Marketing, 37(4), $12-$ 18.

Strick, M., Holland, R.W., van Baaren, R.B. and van Knippenberg, A. (2012), Those who laugh are defenseless: How humor breaks resistance to influence, Journal of Experimental Psychology: Applied, 18(2), 213-223.

Surprenant, C.F. and Solomon, M.R. (1987), Predictability and personalization in the service encounter, Journal of Marketing, 51 (April), 73-80.

Szabo, A. (2003), The acute effects of humor and exercise on mood and anxiety, Journal of Leisure Research, 35 (2), 152-162.

Söderlund, M. and Sagfossen, S. (2017), The depicted service employee in marketing communications: An empirical assessment of the impact of facial happiness, Journal of Retailing and Consumer Services, 38, 186-193.

Söderlund M., Oikarinen, E.-L. and Heikka, E.-L. (2017), Jokes in the store and its effects on customer satisfaction, The International Review of Retail, Distribution and Consumer Research, 27 (3), 260-283.

Wanzer, M.B. and Frymier, A.B. (1999), The relationship between student perceptions of instructor humor and students' reports of learning, Communication Education, 48 (1), 48-62.

Webster, C. and Sundaram, D.S. (2009), Effect of service provider's communication style on customer satisfaction in professional services setting: The moderating role of criticality and service nature. Journal of Services Marketing, 23 (2), 103-113. 
Weinberger, M.G. and Gulas, C.S. (1992), The impact of humor in advertising: A review, Journal of Advertising, 21 (9), 35-59.

Weinberger, M.G. and Spotts, H.E. (1989), Humor in U.S. versus U.K. TV commercials: A comparison, Journal of Advertising, 18 (2), 39-44.

Werner, J.M. and Lester, S.W. (2001), Applying a team effectiveness framework to the performance of student case teams, Human Resource Development Quarterly, 12 (4), 385402.

Wood, R.E., Beckmann, N. and Pavlakis, F. (2007), Humor in organizations: No laughing matter. In: Research companion to the dysfunctional workplace: Management challenges and symptoms, Cheltenham: Edward Elgar Publishing, 216-231.

Wood, R.E., Beckmann, N. and Rossiter, J.R. (2011). Management humor: Asset or liability?, Organizational Psychology Review, 1 (4), 316-338.

Zhao, X., Lynch, J.G. and Chen, Q. (2010), Reconsidering Baron and Kenny: Myths and truths about mediation analysis, Journal of Consumer Research, 37 (August), 197-206.

Ziv, A. (2010), The social function of humor in interpersonal relationships, Society, 47 (1), 11-18. 